\title{
Cognição espacial e intervenções psicopedagógicas no contexto da inclusão
}

\author{
Cristina Lúcia Maia Coelhoi \\ Universidade Federal Fluminense, Brasil \\ Claudio Lyra Bastosii \\ Universidade Federal Fluminense \& Instituto Fluminense de Saúde \\ Mental, Brasil
}

\begin{abstract}
Resumo
Ao longo do tempo, o conceito, a análise e a atenção prática das deficiências intelectuais e do desenvolvimento (DID) sofreram mudanças, ao se deslocarem de paradigmas médico-psicológicos para incluir enfoques educacionais. O objetivo deste estudo é analisar o impacto de intervenções baseadas na avaliação interativa com alunos com DID - com uso de programas computacionais e práticas como a construção de maquetes - na estimulação do desenvolvimento cognitivo potencial, nas dimensões visuoespaciais e lógicas. $\mathrm{O}$ texto constata que o potencial cognitivo de alunos com DID pode ser manifestado através de intervenções mediadas com ênfase nos processos metacognitivos, interacionais e afetivos. Ao destacar as possibilidades de expressão de funções cognitivas, como a espacial - em níveis bidimensionais e tridimensionais -, foi possível desenvolver o potencial de simbolização e abstração dos alunos. A linguagem tecnológica - como o Google Street View - se mostrou uma ferramenta da cultura contemporânea facilitadora na aprendizagem dos alunos com deficiência intelectual.
\end{abstract}

Palavras-chave

Deficiência intelectual e do desenvolvimento; Educação inclusiva; Tecnologia; Habilidades visuoespaciais

\section{Introdução}

Um mundo inclusivo é um mundo no qual todas as pessoas têm acesso às oportunidades de ser e estar na sociedade. Assim, se, por um lado, 
a exclusão pode ser entendida como um descompromisso político com o sofrimento do outro (Sawaia, 2008), a inclusão significa, por outro, humanizar práticas. O espaço escolar assume um papel significativo, não só para o desenvolvimento cognitivo e social dos alunos - sejam eles especiais ou não -, mas também para sua saúde psíquica, pois ela é o primeiro lugar social promotor de separação entre a criança e a família, estabelecendo um importante elo com a cultura.

No contexto contemporâneo, a presença de alunos com deficiências intelectuais e do desenvolvimento (DID) em ambientes comuns de aprendizagem é uma conquista da escola e permite reconhecer as suas potencialidades e compartilhar experiências educacionais significativas, destacando o papel da escola para o desenvolvimento humano nas dimensões intelectuais, simbólicas, afetivas e culturais. Segundo a Associação Americana de Deficiência Intelectual e do Desenvolvimento, crianças com DID apresentam limitações no funcionamento intelectual e no comportamento adaptativo, envolvendo habilidades práticas e sociais que se originam antes dos 18 anos (Schalock et al., 2012). Nesse sentido, a produção de espaços mistos de aprendizagem tem sido uma boa forma de explorar a atividade simbólica, num processo interativo, possibilitando transformações do funcionamento intelectual para todos os alunos, com e sem necessidades especiais.

No referencial teórico Vygotskiano, as funções lógicas não são ensinadas, mas aprendidas nas relações sociais, sendo o aspecto afetivo o sustentáculo dessa relação de ensino-aprendizagem. Neste paradigma, o aspecto subjetivo é sempre relacional e transdisciplinar (Vygotsky, 2003). Na perspectiva de Cohen (1985), todo conhecimento tem, além da origem social, também propriedades espaciais e temporais. Em síntese, a função cognitiva resultaria da integração do conhecimento espacial e do conhecimento social, assim como de uma compreensão da natureza física e social do meio ambiente.

Há uma crítica à educação tradicional de alunos com DID baseada apenas no treino de rotinas e funções cognitivas básicas por perpetuar uma pedagogia que tem por base um sujeito descontextualizado, através de ações massificadoras e repetitivas, e um conhecimento reduzido a um simples saber fazer. A predominância da lógica do concreto nas práticas com alunos com 
deficiência intelectual e do desenvolvimento implica uma visão que nega o acesso deste aluno ao plano do abstrato e do simbólico da compreensão (Gomes, 2010). Numa nova perspectiva, vislumbramos uma educação que promova o desenvolvimento das funções cognitivas mais complexas, como a linguagem, o pensamento e a memória (Ferreira, 1994).

A política da inclusão, em grande medida, atende aos alunos essencialmente numa dimensão física, garantindo o seu lugar nas salas regulares. Mas aos níveis de desenvolvimento cognitivo e aprendizagem, efetivamente, muito ainda falta. Ainda vemos alunos formalmente incluídos nas salas de aula sem apoio, com uma participação restrita, limitando-se muitas das vezes ao papel silencioso de exímios copiadores de quadro negro.

Com base na teoria histórico-cultural, espera-se da escola superar as atividades meramente mecânicas, baseadas nas habilidades motoras, perceptivas e de discriminação (Oliveira, 2005). Há evidências de que, uma vez submetidos a uma abordagem de avaliação interativa conjugada a jogos, alunos com DID podem desenvolver alguma flexibilidade mental (Coelho \& Bastos, 2013). Assim, o desafio que se impõe consiste em superar atividades desprovidas de sentido para assumir uma nova postura frente à DID, possibilitando a constituição destes alunos como sujeitos históricos, capazes de apreensão dos bens simbólicos e de desenvolvimento de seu pensamento, e não apenas de suas habilidades. Cabe ao meio escolar - através de práticas interativas e mediadas - o desafio de explorar as esferas da atividade simbólica, num processo dialógico, para possibilitar as transformações do funcionamento intelectual para todos os alunos, com e sem deficiências.

Em geral, as pessoas com DID não utilizam de maneira espontânea estratégias cognitivas que lhes permitam planejar, antecipando as suas próprias ações. Cabe ao professor ou mediador tentar fazer com que o aluno reconstitua essas ações no plano do pensamento e as organize em função do fim que pretende alcançar. Situações concretas e de interesse do aluno podem ser utilizadas para desenvolver a capacidade de antecipação (Gomes, 2010).

Vimos que, ao longo do tempo, o conceito, a análise e a atenção prática da DID modificaram-se, atravessando os paradigmas médicopsicológicos para incluir os enfoques educacionais (Bailey, 1998). A ênfase na prática de diagnosticar e categorizar, consequência de uma perspectiva 
classificatória, tende a restringir o problema à criança. Focalizando nela, as medidas tomadas visam à sua compensação pelo treino especializado. Nos anos 60 e 70 o problema foi reformulado e compreendido como consequência de um ambiente não adaptado às capacidades e às diversidades dos indivíduos, isto é, como uma relação entre o ambiente e o indivíduo. Esta perspectiva ecológica do problema centra-se nas mudanças do sistema escolar e nas estratégias pedagógicas relacionais e pós-positivistas.

\section{A avaliação interativa}

O referencial metodológico do presente trabalho baseou-se na teoria sócio-histórica de Vygotsky (2003), pela qual Haywood e Tzuriel (1992) se nortearam para desenvolverem a avaliação dinâmica ou interativa, que constitui uma inovadora abordagem para avaliar o potencial de aprendizagem de alunos com DID, na medida em que analisa a responsividade do aprendiz. Procedimentos processuais, dinâmicos e interativos permitem a análise de estratégias de resolução de problemas, assim como da sensibilidade do aluno à instrução, dimensionando recursos potenciais do funcionamento cognitivo (Campione, 1989; Lunt, 1994). Utilizando estratégias instrucionais ajustáveis ao desempenho do aprendiz, o mediador ajuda a revelar o seu desempenho potencial, fazendo-o alcançar um grau crescente de autonomia. Atribui ênfase aos processos cognitivos, em oposição à ênfase nos produtos. Fundada no conceito de zona de desenvolvimento proximal, a avaliação interativa relaciona desenvolvimento, interação social e ambiente sociocultural.

Como um processo sistêmico, a avaliação interativa visa modificar o funcionamento cognitivo através da assistência de um mediador. Baseia-se na teoria da modificabilidade estrutural cognitiva (SCM) de Feuerstein (Haywood \& Tzuriel, 1992) e na experiência da aprendizagem mediada que tem como hipótese a capacidade do ser humano de modificar suas funções cognitivas e adaptar-se às demandas das situações de vida. Neste paradigma, os professores se interpõem entre os alunos e a realidade, modificando o set de estímulos, a sua frequência, a intensidade e o contexto, aumentando a sensibilidade do aprendente. Feuerstein (Haywood \& Tzuriel, 1992) sugeriu características necessárias à interação, a saber: a) intencionalidade e reciprocidade: refere-se ao esforço para produzir no aluno um estado de vigilância e o sentimento de competência e autodeterminação; b) mediação 
do significado: refere-se ao aspecto afetivo-motivacional do estímulo; (c) a possibilidade de transcender a necessidade imediata da situação específica para outros objetivos; (d) regulação e controle dos comportamentos impulsivos.

\section{As intervenções nas habilidades espaciais: os espaços sociais e físicos}

Os ambientes formais de aprendizagem, ao longo da história, têm se apoiado em recursos como livros e, sobretudo, na linguagem oral. Entretanto, o desenvolvimento de uma criança e suas formas de expressão dependem de inúmeros elementos que podem não estar traduzidos na linguagem verbal. A ideia de intervenções através de outras linguagens, com imagens e material concreto, pode significar uma alternativa ao desenvolvimento dos alunos com DID.

As habilidades são o resultado de múltiplas combinações de conhecimentos prévios e tarefas que um indivíduo é capaz de fazer e das informações que obteve a partir dessas combinações. A habilidade espacial envolve pensar em imagens, bem como as capacidades de perceber, transformar e recriar diferentes aspectos do mundo visual e espacial. Alta habilidade espacial envolve sensibilidade para detalhes visuais, esboço de ideias graficamente e orientação no espaço tridimensional. Visando investigar a habilidade espacial de alunos com DID, um estudo concluiu que o desempenho dos alunos na representação espacial - na construção de mapas e rotas - foi mais preciso em espaços internos do que em espaços externos à escola e naqueles mais familiares e limitados (Murakoshi, Yamaguchi, \& Matsumoto, 2004).

De acordo com Choi (2001), as habilidades espaciais compreendem categorias como: rotação mental, percepção espacial e visualização espacial. A rotação mental é a habilidade de manipular, rotacionar, torcer ou inverter objetos tridimensionais; o indivíduo deve ser capaz de visualizar mentalmente os objetos em posições diferentes. A percepção espacial refere-se à habilidade de determinar relacionamentos espaciais a partir de informações visuais. E a visualização espacial consiste na manipulação de problemas visuais complexos imaginando os movimentos relativos das partes internas de 
uma imagem. Podemos ainda destacar as relações espaciais e a orientação espacial. As relações espaciais consistem nas relações que podem ser estabelecidas através de elementos dispostos no ambiente, podendo-se utilizar pontos de referência. A orientação espacial consiste na habilidade de orientar-se no espaço à medida que objetos ou eventos são apresentados (Seabra \& Santos, 2004).

A respeito da percepção e representação do espaço pela criança, a teoria piagetiana reconhece a relação entre as estruturas perceptivas e as operatórias mais complexas da inteligência. De acordo com Piaget (1974), a construção espacial, inicialmente, se prende a um espaço sensório-motor, e em seguida ao espaço operatório, precedido pelos espaços simbólicos, representativos e intuitivos. Em suma, o processo de construção do espaço é engendrado pelas atividades perceptivas, representativas e operatórias, resultando num caminho que procede da ação à operação. Piaget admite que, durante os primeiros meses do desenvolvimento da criança, o objeto não existe fora da sua ação e somente a ação the confere suas qualidades constantes. De início, a criança concebe o espaço topologicamente, uma reunião de espaços fragmentados, sem relacionar uns objetos com os outros, e as fronteiras são fixadas pelo campo perceptual (Oliveira, 2005). Na elaboração das relações espaciais, da mesma forma, no começo apenas existe um espaço prático ou, mais precisamente, tantos espaços práticos quanto os supostos pelas diversas atividades do sujeito. Posteriormente 0 objeto já é construído como substância permanente, independente da atividade do eu. Assim, a criança constrói a realidade mediante o relacionamento do objeto com o espaço e desenvolve a noção de símbolo mediante a imitação e o jogo. $O$ desenho constitui um tipo de representação espacial e, assim, o espaço gráfico em uma das formas do espaço representativo. Nesta perspectiva, o aspecto cognitivo se refere à estruturação da conduta e o aspecto afetivo à regulação da energia interna. Antes do período das operações concretas, o sujeito não consegue coordenar o seu ponto de vista com os de outros possíveis observadores. A passagem dos grupos práticos aos grupos subjetivos e destes aos grupos objetivos envolve uma exploração contínua. Ou seja, transitar do fenômeno egocêntrico para a constituição de um universo formado de objetos permanentes, com deslocamentos coordenados. 
Para Paour (1992), sujeitos com DID, se treinados, mostram um claro desenvolvimento da plasticidade intelectual. $O$ treinamento induz a construção de estruturas lógicas que não teriam sido construídas espontaneamente. Estes ganhos intelectuais induzidos são verdadeiramente de natureza estrutural. O uso de mídias como a Internet na área de ensino tem sido uma ferramenta indispensável para a difusão e intermediação de conhecimento. Partindo do uso dessas tecnologias hipermídias, o projeto de pesquisa e extensão que gerou o presente trabalho na área de cognição e desenvolvimento de alunos com DID trabalha com a noção de identificação do espaço físico na perspectiva dos alunos.

Seymour Papert (1985), ao elaborar o programa LOGO como veículo catalizador de aprendizagem, promove uma oportunidade ao aluno de trabalhar seu erro num sentido benéfico. Mais especificamente, a implementação da proposta construtivista com a linguagem de programação - com o LOGO - supõe que o professor perca o status de exclusivo repassador de conteúdos, compreenda as ideias de seus alunos e possa intervir adequadamente para cooperar com a aprendizagem de seus alunos. Nesta linguagem de programação a dinâmica educacional envolve o aluno $e$ o seu desenvolvimento intelectual.

O objetivo deste estudo é analisar o impacto de intervenções lúdicopsicopedagógicas com apoio de tecnologias hipermídias baseadas na avaliação interativa com alunos com DID, como uso de programas computadorizados e práticas de construção de maquetes e material concreto, na aplicação do seu potencial cognitivo nas dimensões visuoespaciais e lógicas.

\section{Método}

A metodologia do trabalho baseou-se nos princípios da avaliação interativa. Realizaram-se intervenções com práticas lúdicas em pequenos grupos e/ou individualizadas nas salas de recursos, privilegiando aspectos intelectuais, simbólicos e espaciais do desenvolvimento. A mediação singularizada se fez necessária em intervenções que envolviam dimensões intelectuais como o raciocínio lógico, espacial e a flexibilidade mental. 
Os sujeitos da pesquisa foram dois alunos do sexo masculino e três do sexo feminino, de 11 a 15 anos, do $3 .^{\circ}$ ao $6 .^{\circ}$ ano de escolaridade, com DID, de uma escola pública do Rio de Janeiro de uma região considerada em desvantagem social. Os alunos frequentavam a sala regular e a sala de recursos multifuncionais. Suas habilidades sociais e comunicativas eram razoáveis.

Os instrumentos utilizados foram: programas Google Street View, Google Maps e Google Earth; a Caixa-Escola, que foi projetada, a partir da teoria construtivista de Piaget, pelo Centro de Estudos Psicopedagógicos PróSaber; mais especificamente por Lacombe (s.d.); maquetes, plantas, rotas e mapas.

A pesquisa recebeu parecer positivo do comitê de ética da UFF e os termos de consentimento dos responsáveis pelos alunos foram aplicados previamente.

\section{A intervenção}

A proposta do subprojeto "Trabalhando a espacialidade" foi inspirada em um dos alunos com deficiência intelectual, muito tímido, porém com autonomia suficiente para ir sozinho à escola - com muita frequência deixa de saltar do ônibus no ponto da escola, se perdendo na cidade. Em conjunto com a professora da sala de recursos e o grupo de pesquisa do projeto "Cognição em Movimento" visávamos compreender as representações dos alunos acerca dos espaços vividos e verificar a aplicabilidade do potencial da habilidade espacial dos alunos após intervenções. As intervenções foram realizadas através de encontros semanais, durante três meses, entre os bolsistas que atuavam como mediadores e os alunos. O subprojeto se propõe a estudar como o aluno com DID se vê no contexto da sociedade através de suas percepções e representações dos espaços, como de suas residências, do espaço escolar, do seu entorno, vizinhança e deslocamentos.

$O$ procedimento de avaliação interativa foi delineado incluindo as seguintes fases: Inicial Sem Ajuda (SAJ), Assistência (ASS) e Manutenção (MAN). No design da pesquisa, o sujeito funciona como seu próprio controle, com medidas antes e após a mediação. Após instruções, a fase SAJ foi aplicada com as atividades sem nenhuma ajuda do examinador, com o 
objetivo de termos uma linha de base na qual se avalia o desempenho real do aluno, ou seja, seu desempenho quando trabalha sozinho, de forma independente, segundo instruções. Na fase de assistência, o mediador atua junto ao aluno, e na fase de manutenção novamente observamos o desempenho do aluno sem a mediação.

A intervenção seguiu um protocolo que constou de cinco etapas através das quais identificamos como os alunos percebiam as características espaciais, relações espaciais e representacionais (p. ex. localização, sequência, proximidade, separação, direção, distância, etc.) dos seus ambientes conhecidos, como o bairro, a escola, suas residências e o entorno.

A primeira etapa: A reprodução da planta baixa de suas residências e da escola. Os pesquisadores propõem que os alunos façam o registro gráfico (planta baixa) da sala, da escola e de suas residências tendo como auxílio anotações anteriores e livros didáticos contendo figuras planas de ambientes (interiores). O desenho tem o intuito, também, de perpassar o modo como o aluno compreende seu ambiente, o que valoriza e qual a sua perspectiva sobre tal. Assim sendo, os pesquisadores solicitam que cada um explique oralmente o seu registro. Ao perguntarmos o que seria uma planta baixa, nenhum dos alunos soube responder. Deste modo, apresentamos uma resposta simples aos alunos: "Planta baixa seria como observar a sua escola ou casa do alto, retirando o telhado". A partir desta resposta, os alunos desenharam da maneira que compreenderam; alguns conseguiram estruturar um esboço de uma planta baixa, porém outros desenharam a residência observada de "frente" e não do "alto", como proposto. Durante a execução das plantas, todos expressaram suas impressões sobre a escola, suas casas e as dos colegas, comentando sobre as pessoas e sobre os espaços que frequentavam. Cada aluno foi capaz de apresentar a organização espacial de sua escola e de sua casa e, em consequência, suas relações sociais e familiares.

A segunda etapa: Rota entre a residência e a instituição escolar. Nesta etapa foi solicitado aos alunos que reproduzissem, através de um desenho, a rota entre suas residências e a escola destacando pontos de referência do trajeto. Foram observadas muitas distorções, revelando dificuldades em reproduzir a distância e a ordem destes estabelecimentos, na representação da maioria dos alunos. Mas, aos poucos, eles foram falando dos pontos de 
referência, como padarias da esquina, uma figura numa praça, etc., e foram acertando, com a mediação dos bolsistas. Todos os alunos moram nas comunidades ao redor da escola, que se caracterizam por serem muito carentes e cuja organização geográfica não é muito estruturada e linear. Muitas vezes não havia ruas, mas ruelas e becos, dificultando a elaboração das rotas. Nesta atividade, os alunos puderam representar o espaço físico que permeia o seu cotidiano nos seus deslocamentos para a escola. Alguns se deslocam a pé, outros de ônibus. Mesmo vivenciando diariamente a rota de casa para a escola, não sabiam o nome de nenhuma das ruas pelas quais passavam e demonstraram não observar detalhes importantes para a sua orientação. Dois alunos não souberam nem mesmo o nome da rua de suas residências.

A terceira etapa: A mediação com programas computadorizados. Com auxílio do programa Google Street View, através de imagens estáticas, buscamos localizar no mapa as suas residências, a instituição escolar e as rotas que faziam todos os dias. Assim, observamos o espaço e a rota que cada aluno desenhou com as suas particularidades e características. O Google Street View é um recurso do Google Maps e do Google Earth que disponibiliza vistas panorâmicas de $360^{\circ}$ na horizontal e $290^{\circ}$ na vertical e permite que os usuários vejam partes de algumas regiões do planeta ao nível do chão/solo. Nesta etapa tivemos dificuldades em localizar as residências, pois estas se encontravam em locais de difícil acesso. Assim, os alunos puderam reconhecer o espaço em que eles vivem e a rota que percorrem cotidianamente na ida para a escola, observando todos os detalhes que a ferramenta do Google Street View oferece.

Em seguida, realizamos uma análise comparativa entre a rota desenhada pelos alunos e a rota real entre a escola e suas residências. $\mathrm{Na}$ comparação, analisaram-se as distorções e os pontos de referência na rota dados pelos alunos. Com a ajuda dos mediadores, o grupo pode manusear os sites e programas e reconhecer suas casas com muito entusiasmo. Nesta atividade os alunos puderam localizar o espaço físico que permeia o seu cotidiano familiar. Através do Google Street View foi possível obter na realidade o que se conseguiria com a rotação mental, que é a habilidade de manipular, rotacionar, torcer ou inverter objetos tridimensionais. As casas de dois alunos não puderam ser localizadas, nem a rota que desenharam, 
porque o Google Street View não estava disponível para o bairro em que eles moravam; outros visualizaram de forma limitada, através de pequenos pontos de alguns bairros, pois o local não havia sido fotografado em sua totalidade.

Nesta fase ASS (assistência), era oferecido pelos mediadores baseado nos pressupostos da avaliação interativa - um suporte instrucional ajustável ao desempenho do aluno, com o objetivo de melhorar as condições de avaliação e, consequentemente, favorecer a revelação de indicadores de desempenho potencial e de autonomia. A mediação era realizada através de níveis de ajuda crescentes, regulados de acordo com a necessidade do aluno, a saber: do fornecimento de pistas (prompt), instruções passo-a-passo, demonstração, sugestões, feedback sistemático, informativo e analítico, reforço com mapas impressos, desenhos, estímulo à autorregulação, reforço aos acertos, questionamento sobre os erros. A utilização de estratégias de apoio e afetivas (manutenção da motivação, sentimentos de confiança, controle da ansiedade) foi fundamental, considerando que alunos com deficiência intelectual geralmente apresentam pouco domínio de estratégias de aprendizagem (cognitivas e metacognitivas). Usando o programa Google Earth, os alunos tinham a possibilidade de compreender o espaço geográfico mais próximo e mais abrangente (urbano) em que vivem, pois o programa possibilita a visualização do globo terrestre em sua totalidade. Através desta experiência, os alunos puderam perceber o local que habitam com a divisão territorial em países, estados, municípios, bairros e ruas. Com o uso dessas ferramentas multimídias, os alunos perceberam a divisão espacial de forma lógica e estratégica para auxiliar, situar, demarcar os lugares onde residem numa determinada ordem no espaço demográfico.

Em seguida, na intervenção com a ajuda dos mediadores, humanos e não humanos (o recurso tecnológico do Google Street View), solicitamos aos alunos que refizessem as rotas identificando referências pessoais. Os alunos conseguiram esboçar novamente, no papel, a rota e os novos pontos de referência básicos encontrados - como uma padaria, bar, mercado, posto de gasolina, posto de saúde, revendedora de carros, ponto de ônibus, etc. -, que foram fundamentais para a elaboração de uma rota mais precisa. A fase MAN (manutenção) teve por objetivo avaliar o nível de desempenho do aluno sem intervenção para verificar o efeito da mediação e a extensão, pelos quais os sujeitos aprenderam e generalizaram princípios e estratégias de solução de problemas. Computaram-se os desempenhos nas fases SAJ, ASS e MAN. 
A quarta etapa: As maquetes da escola e das residências. No momento em que a escola comemorava 100 anos de existência, foi proposta ao grupo de alunos a elaboração coletiva de uma maquete que pudesse representar a escola e suas residências. A partir da planta baixa iniciaram-se os trabalhos. Nas atividades, muitos temas foram abordados, como a ocupação dos espaços pela comunidade escolar e os seus significados. Estava em cena a capacidade de orientação temporal e espacial dos alunos envolvidos. O passeio pela própria escola e várias anotações realizadas por eles proporcionaram um recurso vivencial inicial para a construção da maquete.

Segundo Almeida e Passini (2002), a construção da maquete serve de base para explorar a projeção do espaço vivido para o espaço representado. Ela é a forma material de se trabalhar alguns conceitos da geografia, proporcionando a ação do indivíduo sobre o objeto e, conseqüentemente, interferindo na sua formação e compreensão dos conteúdos e do mundo. Dá então a visibilidade da conexão entre a ação do homem e o espaço físico. $\mathrm{Na}$ construção da maquete, supõe-se que o aluno analisará a questão espacial do ambiente, a ordem lógica da organização, de forma prática e concreta. Considerando que a escola é um dos espaços cotidianos em que o aluno mais participa, partimos do pressuposto que é relevante o processo de conhecimento da sua própria escola, de como são organizadas e desenvolvidas suas funções e atividades de forma representacional. Assim, este trabalho será o ponto de partida para possibilitar que o aluno conheça e reflita, posteriormente, sobre o mundo global, e sobre toda a universalidade que o rodeia, além das fronteiras escolares (Silveira, 2009).

A maquete da escola foi construída coletivamente pelo grupo. Com o objetivo de contextualizar espacialmente a escola no bairro e as possibilidades de deslocamento dos alunos de casa para a escola, surgiu a ideia de realizarmos as maquetes das residências dos alunos. Cada aluno foi capaz de trazer para o grupo a organização espacial de suas casas e, em consequência, suas relações familiares. Visando aprofundar a representação de suas residências e as suas capacidades de expressarem suas vivências familiares de uma forma não-verbal, iniciamos a proposta de construção de maquetes com material simples, como bulas de remédios e caixas vazias, de papelão, de alimentos. Cada aluno realizou sua maquete e a preencheu com 
os móveis principais em cada cômodo. Por exemplo, na sala reproduziram televisão, sofás, mesas, etc., e sempre fazendo referências aos seus familiares e hábitos cotidianos. Podemos admitir que, para construir a maquete, torna-se importante que o aluno compreenda o espaço vivencialmente. Para tanto, uma conversa sobre as suas residências e as pessoas que lá viviam foi muito significativa.

Buscamos neste trabalho estimular os alunos para que retratassem da maneira mais fiel o local de suas residências. Por exemplo, a aluna E., que reside em uma comunidade carente, com níveis elevados de criminalidade, nos informou que tem dois acessos para a sua habitação: um mais seguro, porém mais distante; e outro mais rápido, porém, segundo a mãe da aluna, mais perigoso. Deste modo, foi retratado um espaço físico com estas características numa maquete. Vale registrar que a motivação da aluna ao realizar o trabalho a levou a construir, além de sua casa, os dois acessos e alguns prédios do entorno de sua residência. Todas as produções foram registradas através de vídeos e fotografias e depois foram objeto de conversas e debates.

A quinta etapa: Caixa-Escola Aberta e a indução de estruturas lógicas nos alunos com DI. Considerando o desenvolvimento cognitivo de alunos com DID, Paour (1992) admite que este grupo manifesta fixações no nível préoperatório. Entretanto, relata que há evidências que apontam que tais sujeitos são caracterizados por uma relativa plasticidade desenvolvimental. $\mathrm{O}$ autor ressalta que condições específicas de indução constituem um instrumento efetivo para ajuda às pessoas com deficiência a terem acesso a um nível de pensamento operatório concreto que não conseguiriam espontaneamente. Segundo Paour (1992), no nível cognitivo, as pessoas com DID são caracterizadas por uma discrepância crônica entre o nível do desenvolvimento de suas competências cognitivas e os recursos disponíveis para aplicá-los espontaneamente. Assim, entendemos que as intervenções psicopedagógicas neste grupo são fundamentais para o seu desenvolvimento.

Em continuidade à abordagem sobre a orientação espacial, realizamos atividades pautadas na caixa-escola, buscando a integração dos aspectos espaciais, afetivos e cognitivos na aprendizagem. A caixa-escola fechada tem a aparência de um prédio, aberta possui um espaço interno, onde seriam as salas de aula e outros espaços, incluindo os externos, como pátios. $\mathrm{Na}$ 
proposta de aferição do desenvolvimento cognitivo, a ideia é que ela seja construída pelo aluno à sua maneira. Não possui divisão ou paredes fixas além das paredes externas da caixa; no piso existem furos onde a criança encaixará as paredes, definindo os espaços de acordo com seu desejo e modificando o quanto sentir necessidade. As salas de aula podem ter diferentes tamanhos e diferentes posições, bem como o banheiro feminino e masculino, sala da diretoria, secretaria, etc. O pátio da escola é pintado com tinta de lousa para que a criança possa traçar quadras, amarelinhas, etc. As peças confeccionadas em madeira que compõem a caixa-escola são: uma caixa em formato de escola que se abre criando dois espaços, um interno e um externo; divisórias "paredes"; quadros de giz; carteiras; cadeiras; mesas; vasos sanitários; lavatórios; alunos (de diferentes sexos e tamanhos) e professores confeccionados em arame e lã colorida que permitem serem moldados - como, por exemplo, ficarem de pé ou sentados. Considerando que o comportamento espontâneo padrão da criança reflete o nível do seu desenvolvimento, ou seja, sua estrutura cognitiva, propomos a primeira atividade, que foi realizada com os alunos F. e P. individualmente.

Solicitamos aos alunos que reproduzissem, de acordo com o material apresentado, uma sala de aula. F. optou por reproduzir a sua própria sala, distribuindo as mesas e cadeiras por todo o espaço, porém sem delimitar as paredes ao fundo. Como o aluno não progredia sozinho, necessitando de estímulos, fizemos perguntas como: "Onde você se senta?", "Quais os alunos próximos a você?" e "Qual seria a disciplina ministrada?". O aluno F. respondeu que se sentava na primeira fileira na mesa do centro; na segunda pergunta referiu-se às colegas P., E. e S. e representou-as com bonecas, sendo fiel à cor da pele e cabelo, ou seja, observando os detalhes. $O$ aluno não quis responder sobre o conteúdo da aula. Utilizamos a linguagem escrita e não mais a ação. F. então produziu um pequeno texto sobre a disciplina de Português, na qual gostaria de estar presente. Vale lembrar que o aluno tem domínio da escrita, como foi observado em outros alunos nos trabalhos realizados.

A aluna P. idealizou a sua sala dispondo os alunos no espaço com cadeiras e mesa, em frente às quais cada aluno teria um quadro, além do professor. Segundo P. cada aluno, antes de escrever no caderno, escreveria no seu próprio quadro. Diferente de F., P. representou os alunos/bonecos em 
todas as cadeiras e disse o nome de alguns amigos de turma e de outras turmas. Para P., a sua escola ideal teria apenas um professor para todas as disciplinas. Este fato demonstra que a aluna se identifica com o modelo educacional do primeiro ciclo do fundamental, embora já esteja cursando o ensino médio. Outra suposição seria o fato de a aluna ainda não ser alfabetizada, embora deseje dominar a escrita e a leitura. O fato de sua irmã de sete anos já dominar a linguagem escrita e oral alimenta o seu desejo.

$\mathrm{Na}$ segunda atividade, pedimos aos alunos individualmente que representassem o recreio. Onde ficavam? Com quais amigos? O que faziam? F. demonstrou ficar isolado, apenas copiando da amiga P. as matérias das aulas perdidas, por chegar atrasado com frequência na instituição. $\mathrm{Na}$ área externa, pedimos que F. representasse a escola. Ele dividiu os banheiros entre masculino e feminino, com grande exatidão. P. representou o mesmo espaço, porém colocou as amigas de sua sala e de outras juntas em um banco,sentadas, conversando. Ambos representaram a sala de recursos que frequentam, colocando uma pequena turma atendida pela professora L., com a qual mostram profunda identificação.

Visando aprofundar a avaliação, introduzimos a proposta de explorar o potencial cognitivo dos alunos. Propomos questões quanto à classificação, inclusão e interseção de classes, usando o número de alunos, professores, sexo, faixas etárias e tipos físicos. Perguntamos, por exemplo: quantos alunos tem a turma? Em seguida perguntávamos: qual grupo tem mais alunos, o do sexo masculino ou o do sexo feminino? Todos foram bem sucedidos nestas questões. Porém, ao perguntarmos se havia mais alunos do que meninas, os alunos com deficiência intelectual ficavam confusos e respondiam que era o grupo de meninos, pois era o que tinha o maior número comparado ao grupo feminino. Isso se explica pela inexistência da noção de inclusão de classes devido à ausência da percepção de que meninos e meninas são subclasses que se incluem numa classe mais ampla, ou seja, a classe dos alunos. Considerando o pensamento pré-operacional do grupo, os mediadores insistiram em mostrar a relação inclusiva entre os grupos. No caso da multiplicação lógica, estimulava-se os alunos a trabalharem a operação que consiste em encontrar a maior classe (alunos) que esteja contida nestas duas classes ao mesmo tempo. Dito de outra forma, encontrar o conjunto comum a duas classes. Por exemplo, alunos do sexo masculino e morenos. Portanto, 
deve-se excluir o grupo do sexo feminino e o grupo de alunos loiros. Através das marcações dos furos sobre o piso da caixa-escola para fixar às paredes, foi possível a passagem do nível bidimensional (planta baixa) para o tridimensional (o ambiente da caixa).

Caixa-Escola Fechada: Com a caixa-escola fechada, pedimos aos alunos que localizassem a escola, mas eles não souberam dizer o nome da rua na qual ficava situada. Através de estímulos como consulta aos mapas, os alunos conseguiram retomar os pontos de referências tal qual já havíamos trabalhado nas atividades das maquetes e pelo Street View, tais como: o shopping ao lado da instituição, o posto de saúde, o posto de gasolina e os dois supermercados perto da escola. Nesta atividade, foram realizadas as seguintes perguntas ao grupo: A escola fica mais perto do shopping ou de sua residência? O shopping fica à direita ou à esquerda da escola? Quais os pontos de referência que ficam em frente da escola? O posto de saúde é mais perto ou mais longe da escola, comparado ao posto de gasolina?

\section{Análise dos resultados}

O mais significativo no uso de instrumentos como plantas baixas, maquetes, rotas e caixa-escola, com a mediação da tecnologia no processo de avaliação/ intervenção, consistiu em levar o aluno a se expressar através da ação e da percepção espacial. Vivenciar simbolicamente seu contexto escolar, seu espaço familiar e sua comunidade através da ação e da representação espacial possibilitaram a estes alunos rever suas ideias e sentimentos induzindo estruturas lógicas no pensamento. Para além destes fatos, a análise de suas ações e representações nos permitiu entender suas histórias pessoais, identificações, vínculos afetivos e socioculturais.

Os dados obtidos foram analisados qualitativamente considerando que havia relatos de observações, gravações, vídeos e fotos das intervenções. Para além das respostas e relatos dos alunos, consideraram-se suas reações emocionais não verbais - tanto frente às atividades propostas quanto às suas reações aos mediadores - e suas disposições físicas.

As intervenções - por seu caráter lúdico - permitiram aos alunos com DID, do ponto de vista do significado, reviver suas experiências e, do ponto de vista do significante, o aspecto simbólico das atividades permitiu a linguagem 
pessoal, viva e dinâmica indispensável para a expressão da subjetividade, intraduzível somente na linguagem oralizada.

$\mathrm{Na}$ intervenção interativa, estratégias de apoio e afetivas (manutenção da motivação, sentimentos de confiança, controle da ansiedade) foram fundamentais, considerando que o aluno DID com histórico de baixo rendimento escolar apresenta pouco domínio de estratégias de aprendizagem cognitivas e metacognitivas. Neste paradigma, os aspectos afetivoemocionais tornam-se relevantes, ativando habilidades metacognitivas. A atuação do mediador caracterizou-se por colocar o pensamento do sujeito em evidência tornando-se, ele próprio, objeto de reflexão. Essa ação recursiva denominada metacognição é relevante em situações de aprendizagem (Spinillo \& Lautert, 2008) e atua como responsável pela tomada de consciência e como mecanismo de autorregulação.

Os aspectos cognitivos dos alunos puderam ser analisados através das configurações realizadas na caixa-escola com as divisórias como acesso das salas de aula aos outros cômodos, colocação das carteiras, quadros e o desenho da planta baixa da escola. A antecipação das ações mentalmente não foi verificada como um plano verbalizado ou desenhado, apontando para a predominância de um pensamento pré-operatório dos alunos com DID. Com as mediações foram construídas condições específicas que favoreciam a plasticidade intelectual, gerando uma possibilidade efetiva aos alunos com deficiência de terem acesso a um nível de pensamento operatório concreto que não conseguiriam espontaneamente. O potencial dos alunos quanto à classificação, inclusão e interseção de classes, através da contagem de elementos, classificação por sexo, faixas etárias e categorias profissionais, foi explorado, assim como diferentes níveis de dimensionalidade do espaço.

A análise comparativa das plantas e rotas antes e depois da intervenção permitiu verificar os avanços cognitivos dos alunos. Os resultados indicaram que na fase Sem ajuda os alunos apresentaram uma habilidade espacial limitada com desenhos de plantas e rotas e a organização do espaço da escola na caixa-escola com muitas distorções. Após a intervenção, solicitou-se que refizessem as rotas e o desenho das plantas, as maquetes e as configurações da escola identificando referências pessoais. As rotas e pontos de referência após a intervenção foram significativamente mais precisos. 
Considerando que a durabilidade é considerada um critério sólido para mudanças cognitivas estruturais, os efeitos das competências adquiridas foram avaliados depois de um período. A diferença de resultados entre 0 esboço do mapa ou a planta baixa e as tarefas que apontam referências, como as rotas, implicam que as duas tarefas exigem diferentes representações espaciais e processos cognitivos. A diferença entre os pontos de referência dentro e fora da escola indicou que os estudantes tinham uma melhor compreensão da representação espacial quando o espaço era mais limitado e familiar - como, por exemplo, as suas residências e as salas que frequentavam na escola.

$\mathrm{Na}$ confecção das rotas antes da intervenção, foi possível identificar que o tipo de representação espacial dos trajetos rotineiros dos alunos - isto é, a confecção de seus mapas pessoais - seguia uma lógica temporal sequencial. Ou seja, o que eu faço agora, depois e sucessivamente, e não um mapa espacial bidimensional propriamente dito. Em concordância com a literatura (Frenkel \& Bourdin, 2009; Mengue-Topio, Courbois, Farran, \& Sockeel, 2011), observamos que os alunos tendiam a seguir rotas padronizadas e sem uma representação configurativa do local. Com a intervenção auxiliada por Google Street View, foi possível, ainda que de forma básica, apresentar aos alunos uma visão objetiva e menos autorreferenciada dos espaços. Os pontos de referência foram destacados, assim como as idéias de proximidade e as noções da área como um todo.

\section{Considerações finais}

Embora o trabalho visasse as habilidades espaciais, as intervenções realizadas colocaram em cena competências sociais, expressivas, afetivas, psicomotoras, lógicas e linguísticas, considerando que as dimensões cognitivas não atuam de forma fragmentada, mas de forma integrada. $O$ desempenho dos alunos nos eventos sociais da escola nos permite supor que o fortalecimento das capacidades espaciais possa vir a desencadear um maior senso de pertencimento dos alunos com DID ao seu grupo, à sua escola, à sua família, à sua comunidade e à sua cidade. Considerou-se que as intervenções direcionadas ao desenvolvimento da habilidade espacial possibilitaram a experiência de vivenciar com autonomia e independência os deslocamentos físicos dos alunos com DID fundamentais para sua 
funcionalidade, tanto no meio escolar como familiar. Podemos admitir que os potenciais cognitivos dos alunos com DID não se manifestam espontaneamente e, em grande medida, exigem mediações psicopedagógicas singularizadas ou em pequenos grupos.

Ao desenvolver uma revisão da literatura contemporânea sobre acesso de pessoas com necessidades especiais ao computador, Hoppestad (2007) concluiu que houve uma evolução de um modelo médico para um modelo social nos serviços a esta população. O autor admitiu que as tecnologias muitas vezes não alcançam as necessidades das pessoas especiais, principalmente aquelas com severas deficiências. Em um estudo mais recente, Hoppestad (2013) ressaltou a escassez de pesquisas quanto aos métodos para ajudar as pessoas com DID a terem acesso ao computador. Esta situação, segundo o autor, tende a perpetuar a subutilização dos computadores nesta população que é assistida, por exemplo, em hospitaisdia. O autor conclui que as pessoas com DID são muitas vezes negligenciadas e desacreditadas quanto à possibilidade de serem capazes de usar um computador pessoal. Embora haja um esforço das comunidades para aumentar ainda mais a participação das pessoas com DID, há uma escassez de pesquisas referentes a como os adultos com DID podem acessar um computador. Uma vez que a escolarização formal termina, parece haver pouco interesse em apoiar adultos que usam computadores. $\mathrm{O}$ autor ressalta que uma das competências dos profissionais de reabilitação seria a capacidade de ajudar as pessoas com DID a ter acesso ao computador.

A presente pesquisa - ao enfatizar as possibilidades de expressão cognitivas como a espacial - dá uma luz ao potencial de simbolização e abstração dos alunos com DID no cenário da inclusão. A linguagem tecnológica da cultura contemporânea - o uso de Internet, mapas, Google Street View - se mostrou uma nova ferramenta e um facilitador na aprendizagem dos alunos com DID, contribuindo para a promoção de uma educação inclusiva. Vale registrar que os professores - aqueles da sala regular e o da sala de recursos - acompanharam o estudo com muita participação e entusiasmo, o que nos leva a admitir que poderão lançar mão destes recursos na sua prática pedagógica com os alunos estudados. A tecnologia utilizada contribuiu para orientar o desenvolvimento humano, pois opera na zona de desenvolvimento proximal de cada indivíduo por meio da 
internalização das habilidades cognitivas requeridas pelos sistemas de ferramentas correspondentes.

\section{Referências}

Almeida, R., \& Passini, E. (2002). O espaço geográfico: Ensino e representação. São Paulo: Contexto.

Bailey, J. (1998). Medical and psychological models in special education needs. In C. Clark, A. Dyson, \& A. Millward (Eds.), Theorising special education (pp.44-60). London: Routledge.

Campione, J. (1989). Assisted assessment: A taxonomy of approaches and an outline of strengths and weaknesses. Journal of Learning Disabilities, 3(22), 151-65.

Choi, J. (2001). Sex differences in spatial abilities in humans: Two levels of explanation. In J. Vokey \& S. Allen, Psychological sketches (5. ${ }^{a}$ ed.) (pp. 31-38). Lethbridge, Alberta: University of Lethbridge.

Coelho, C., \& Bastos, C. (2013). Habilidade lógico-espacial de alunos com deficiência intelectual: A torre de Hanói como intervenção. Interacções, 26, $\mathrm{n}^{\circ}$ especial, 311-328. Recuperado de http://www.eses.pt/interaccoes

Cohen, R. (1985). The development of spatial cognition. New Jersey: Lawrence Erlbaum Association, Inc.

Ferreira, M. (1994). A prática educativa e a concepção de desenvolvimento psicológico de alunos com deficiência mental (Tese de doutorado). Campinas - São Paulo, Universidade Estadual de Campinas, Faculdade de Educação.

Frenkel, S., \& Bourdin, B. (2009). Verbal, visual and spatio-sequential short-term memory: Assessment of the storage capacities of children and teenagers with Down's syndrome. Journal of Intellectual Disability Research, 53(2), 152-160.

Gomes, A. (2010). O atendimento educacional especializado para alunos com deficiência intelectual. Brasília: Ministério da Educação.

Haywood, C., \& Tzuriel, D. (1992). Interactive assessment. New York: Springer-Verlag New York, Inc.

Hoppestad, B. (2007). Inadequacies in computer access using assistive technology devices in profoundly disabled individuals: An overview of the current literature. Disabil Rehabil Assist Technol, 2(4), 189-199.

Hoppestad, B. (2013). Current perspective regarding adults with intellectual and developmental disabilities accessing computer technology. Disabil Rehabil Assist Technol, 8(3), 190-194. doi: 10.3109/17483107.2012.723239

Lacombe, A. (s.d.). Caixa-casa e caixa-escola: Teoria e prática. Centro de Estudos Psicopedagógicos Pró-Saber. Recuperado de www.prosaber.org.br

Lunt, J. (1994). A prática da avaliação. In H. Daniels (Org.), Vygotsky em foco: Pressupostos e desdobramentos (pp.219-252). Campinas, SP: Papirus. 
Mengue-Topio, H., Courbois, Y., Farran, E. K., \& Sockeel, P. (2011). Route learning and shortcut performance in adults with intellectual disability: A study with virtual environmental. Research in Developmental Disabilities, 32, 345-352.

Murakoshi, S., Yamaguchi, Y., \& Matsumoto, K. (2004). Comparison between sketch map and pointing methods for evaluating spatial cognitive ability of secondary school students with mental retardation. Shinrigaku Kenkyu, 75(4), 347-52. Recuperado de http://www.ncbi.nlm.nih.gov/pubmed/15747555

Oliveira, L. (2005). A construção do espaço segundo Piaget. Sociedade e natureza, 17(33), 105-117.

Paour, J. (1992). Induction of logic structures in mentally retarded: An assessment and intervention instrument. In C. Haywood \& D. Tzuriel, Interactive assessment (pp.119-166). New York: Springer-Verlag New York, Inc..

Papert, S. (1985). Logo: Computadores e educação. São Paulo: Brasiliense.

Piaget, J. (1974). A construção do real na criança. Rio de Janeiro, RJ: Zahar.

Sawaia, B. (2008). Introdução: Exclusão ou inclusão perversa? In B. Sawaia (Org.), As artimanhas da exclusão. Análise psicossocial e ética da desigualdade social (pp.7-13). Petrópolis, RJ: Vozes.

Schalock, R., Borthwick-Duffy, S., Bradley, V., Buntinx, W., Coulter, D., Craig, E., ...Yeager, M.. (2012). Intellectual disability: Definition, classification, and systems of supports (11th ed.). Washington, DC: American Association on Intellectual and Developmental Disabilities, AIDD.

Seabra, R., \& Santos, E. (2004). Proposta de desenvolvimento da habilidade de visualização espacial através de sistemas estereoscópicos. $4^{\circ}$ Congreso Nacional y $1^{\circ}$ Internacional. Rosário, Argentina. Recuperado de https://www.academia.edu/826250/Proposta_de_Desenvolvimento_da_ Habilidade_de_Visualiza\%C3\%A7\%C3\%A3o_Espacial_Atrav\%C3\%A9s_de_ Sistemas_Estereosc\%C3\%B3picos

Silveira, L. (2009). Construção da maquete do espaço escolar. Recuperado de http://portaldoprofessor.mec.gov.br/ fichaTecnicaAula.html?aula=1229

Spinillo, A., \& Lautert, S. (2008). Pesquisa-intervenção em psicologia do desenvolvimento cognitivo: Princípios metodológicos, contribuição teórica e aplicada. In L. Castro \& V. Besset (Orgs.), Pesquisa-intervenção na infância e juventude (pp. 294-321). Rio de Janeiro, RJ: Trarepa/Faperj.

Vygotsky, L. (2003). A formação social da mente. Porto Alegre, RG: Artes Médicas. 


\title{
SPATIAL COGNITION AND PSYCHOPEDAGOGICAL INTERVENTIONS IN THE CONTEXT OF INCLUSION
}

\begin{abstract}
Over time, intellectual developmental disability (IDD) suffered changes concerning its concept, analysis and practice, moving away from a medicalpsychological paradigm to include an educational focus. Within the context of inclusive education, the aim of this study is to analyze the impact of interventions based on interactive assessment with IDD students - using computer programs and practical tasks, as building scale models - in the potential stimulation of cognitive development, specifically in the visuospatial and logical dimensions. This text notes that the cognitive potential of students can be manifested through mediated interventions, with emphasis on metacognitive, affective and interactional processes. Stressing possibilities of expression for cognitive resources, such as spatial functions - in both twodimensional and three-dimensional levels -, it was possible to develop the students' potential of abstraction and symbolization. Technological resources of contemporary culture - such as Google Street View - demonstrated to be effective as facilitating learning tools for students with intellectual disabilities.
\end{abstract}

Keywords

Intellectual disabilities; Inclusive education; Technology; Visual-spatial skills

\section{COGNICIÓN ESPACIAL E INTERVENCIONES PSICOPEDAGÓGICAS EN EL CONTEXTO DE LA INCLUSIÓN}

\section{Resumen}

La discapacidad intelectual sufrió cambios en el concepto, análisis y atención práctica, al pasar de un paradigma puramente médico-psicológico para el enfoque educativo. El objetivo de este estudio es analizar el impacto de las intervenciones basadas en la revisión interactiva con los alumnos con 
discapacidad intelectual - con ayuda de programas de ordenador como modelos de construcción - para estimular el desarrollo en las dimensiones visuoespaciales. Este texto señala que el potencial cognitivo de los estudiantes con discapacidad intelectual puede expresarse a través de la acción mediada con énfasis en los procesos metacognitivo, interaccional y afectivo. Al hacer hincapié en las posibilidades de expresión de funciones cognitivas, como la espacial - en los niveles bidimensionales y tridimensionales -, fue posible desarrollar el potencial de la simbolización y abstracción de los estudiantes. El lenguaje tecnológico - como el uso de Google Street View - resultó ser una herramienta de cultura contemporánea facilitadora en el aprendizaje de los alumnos con discapacidad intelectual.

\section{Palabras-clave}

Discapacidad intelectual; Educación inclusiva; Tecnología; Habilidades visuales-espaciales

Recebido em agosto/2015

Aceite para publicação em março/2016

i Faculdade de Educação, Universidade Federal Fluminense, Brasil.

ii Faculdade de Medicina, Universidade Federal Fluminense \& Instituto Fluminense de Saúde Mental, Brasil.

Toda a correspondência relativa a este artigo deve ser enviada para: Cristina Lúcia Maia Coelho, Rua Major Fróes, $n^{\circ} 67$ São Francisco - cidade de Niterói - Estado do Rio de Janeiro - Brasil - CEP 24365030, E-mail: crismaia84@gmail.com 